\title{
Uma Abordagem Baseada em Robótica e Computação Desplugada para Desenvolver o Pensamento Computacional na Educação Básica
}

\author{
Felipe Oliveira Miranda Cunha ${ }^{1}$, Cristiane Ribeiro do Nascimento $^{2}$ \\ ${ }^{1}$ Universidade Federal da Paraíba (UFPB) - João Pessoa - PB - Brasil \\ ${ }^{2}$ Universidade Estadual da Paraíba (UEPB) - Campina Grande - PB - Brasil \\ \{felipeoliveira.ufpb, cristianeribeiro.ufpb\} @gmail.com
}

\begin{abstract}
This paper presents an approach to teaching the fundamentals of computer science in basic education by combining activities of unplugged computing and robotics. The influence of the approach was evaluated with $3 r d$, 4th and 5th year elementary students. The results show a better performance among participants who received robotic stimuli.
\end{abstract}

Resumo. Este trabalho apresenta uma abordagem para ensinar os fundamentos da ciência da computação na educação básica combinando atividades de computação desplugada e robótica. Avaliou-se a influência da abordagem com estudantes do $3^{\circ}, 4^{\circ}$ e $5^{\circ}$ anos do ensino fundamental 1 . Os resultados evidenciam melhor desempenho entre os participantes que receberam estímulos da robótica.

\section{Introdução}

Diversos países têm discutido a importância da ciência da computação como ciência básica. Israel [Gal-ezer 1999], Canadá [MEO 2008], Estados Unidos [CSTA 2005] e Inglaterra [Csizmadia et al. 2015] defendem o ensino dos fundamentos da computação na educação básica para desenvolver nos estudantes uma maneira computacional de pensar, modelar e resolver problemas de diversas áreas. Csizmadia et al. (2015) afirma que um currículo básico deve contemplar o desenvolvimento do pensamento computacional, que segundo Wing (2006) é o raciocínio articulado aos conhecimentos da matemática, engenharia e ciências que visa o aprimoramento da busca por soluções de problemas.

As atividades desenvolvidas por Tim Bell, Ian H. Witten e Mike Fellows, no livro "Computer Science Unplugged" [Bell et al. 2007], por exemplo, têm o objetivo de ensinar os fundamentos sobre a ciência da computação sem o uso do computador e são uma maneira lúdica de introduzir o pensamento computacional na escola.

Estudos apontam ainda a possibilidade de inserir o pensamento computacional na educação básica por meio da robótica [Oliveira and Araujo 2016], [Da Silva et al. 2016], [Zanetti and Oliveira 2015]. A robótica é um instrumento capaz de desenvolver o pensamento computacional e de promover o aprendizado efetivo dos princípios da computação [Neto et al. 2015], fundamental para crianças em idade escolar. 
VII Congresso Brasileiro de Informática na Educação (CBIE 2018)

Anais do XXIX Simpósio Brasileiro de Informática na Educação (SBIE 2018)

Diante disso, este trabalho apresenta uma abordagem para inserir o pensamento computacional na educação básica por meio do ensino dos princípios da computação envolvendo computação desplugada e robótica educativa.

\section{Abordagem Proposta}

A abordagem consiste na viabilidade de inserir a robótica de maneira complementar a atividade de computação desplugada "Contando os pontos", descrita no projeto CSUnplugged [Bell et al. 2007] como uma proposta para ensinar a linguagem utilizada pelo computador para representar dados, de maneira a tornar efetivo o aprendizado sobre esse assunto. A inserção da robótica foi pensada como um recurso instrucional que promova o efetivo entendimento dos conceitos expostos, tendo em vista a dificuldade que os alunos têm para a assimilação e conversão de números binários, que foi verificada após aulas expositivas.

Diante disso, foi proposto aos alunos do $5^{\circ}$ ano do ensino fundamental, durante as aulas da disciplina de Robótica em uma escola privada em João Pessoa, o desafio de aprender o conteúdo de números binários, construir e programar um robô para posterior aplicação com diferentes turmas e escolas. O grupo trabalhou com a hipótese de que um robô que convertesse números binários em decimais, associando a ludicidade promovida no uso de lâmpadas ligadas e desligadas para representar os estados de dígitos binários, pudesse ser eficiente no aprendizado desse tópico da ciência da computação.

A abordagem foi aplicada com diferentes turmas do $3^{\circ}, 4^{\circ}$ e $5^{\circ}$ anos do ensino fundamental em diferentes escolas para verificar até que ponto o uso da robótica influencia na desenvoltura dos estudantes ao encarar problemas de conversão binária de níveis de dificuldade distintos. $\mathrm{Na}$ aplicação, cada turma foi dividida em dois grupos. $\mathrm{O}$ primeiro grupo participou da atividade desplugada e, em seguida, resolveu problemas de conversão binária. O segundo grupo participou da atividade desplugada e da experimentação do robô para, em seguida, resolver questões de conversão binária.

\subsection{Atividade Desplugada}

A atividade "Contando os pontos" foi aplicada utilizando uma adaptação da atividade original, utilizando cartões contendo imagens de lâmpadas acesa e apagada, associando-as aos conceitos de bit ligado e bit desligado, respectivamente, e que a partir de combinações desses estados é possível representar números e outros dados. Nesse momento, os alunos faziam a conversão binário-decimal e decimal-binária de números aleatórios, conforme Figura 1.

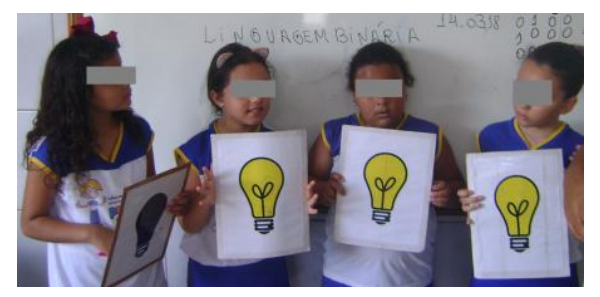

Figura 1. Aplicação da atividade desplugada.

\subsection{Conversão binária com o robô}


VII Congresso Brasileiro de Informática na Educação (CBIE 2018)

Anais do XXIX Simpósio Brasileiro de Informática na Educação (SBIE 2018)

O segundo grupo realizou a atividade de conversão após o estímulo do robô que ensina a conversão binária. Os alunos experimentaram o robô com testes de números aleatórios, conforme Figura 2.

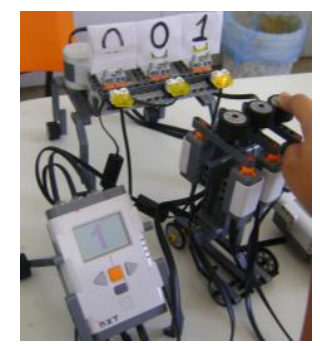

Figura 2. Robô que executa a conversão binária.

O robô utiliza partes do kit tecnológico Lego NXT, motores, sensores de toque, lâmpadas e blocos programáveis. Quando um sensor é ativado ou desativado, o motor correspondente gira $180^{\circ}$ ou $-180^{\circ}$, respectivamente, e apresenta o número binário correspondente e o número decimal equivalente às combinaçãoes de números binários na tela do bloco NXT.

\subsection{Resolução de problemas de conversão binária}

A atividade contemplou problemas de conversão a partir da contagem de pontos em cartas para valores decimais ( $\mathrm{CP} 1$ e $\mathrm{CP} 2)$, de conversão de símbolos de lâmpadas ligada e desligada para valores em decimal (L1 e L2), da conversão binário-decimal (BD1 e BD2) e outros quatro problemas que envolveu a conversão decimal-binário (DB1, DB2, DB3 e DB4). Essa atividade foi aplicada com 59 estudantes do $3^{\circ}$ ano, 49 estudantes do $4^{\circ}$ ano e 30 estudantes do $5^{\circ}$ ano do ensino fundamental $1 \mathrm{em}$ diferentes escolas privadas.

\section{Resultados}

Dos 59 estudantes do $3^{\circ}$ ano que participaram do estudo, 29 não receberam o estímulo da robótica, enquanto que 30 alunos receberam o estímulo. $\mathrm{O}$ grupo de estudantes do $3^{\circ}$ ano que não receberam estímulo do robô obteve bom desempenho nas atividades que demandavam a contagem dos pontos para responder o valor decimal, CP1 e CP2, bem como a atividade de verificar a posição das lâmpadas acesas e apagadas, L1. Entretanto, após a questão L2, o índice de erros aumentou, chegando a 25 na resolução da conversão binário-decimal, B-D2, e o número de acertos caiu para 5 na mesma questão, conforme Figura 3.

Já o grupo de estudantes do $3^{\circ}$ ano que recebeu o estímulo da robótica, apresentou melhores resultados no teste de conversão em relação ao grupo que não interagiu com o robô. Isso foi percebido quando os índices de acertos se mantiveram entre 23 e 30, bem como os índices de erros se mantiveram entre 1 e 7, Figura 3.
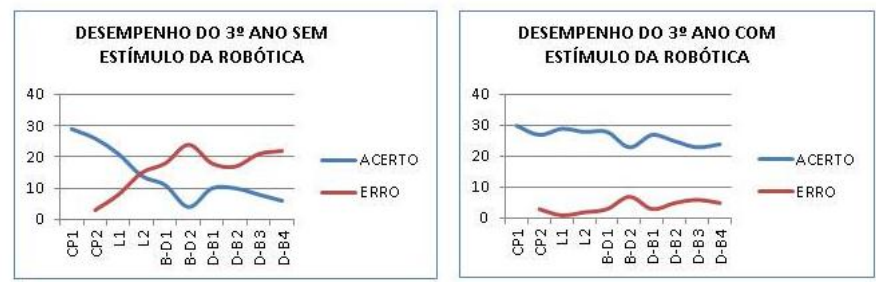
VII Congresso Brasileiro de Informática na Educação (CBIE 2018)

Anais do XXIX Simpósio Brasileiro de Informática na Educação (SBIE 2018)

Figura 3 - Desempenho do $3^{\circ}$ ano.

Em relação ao $4^{\circ}$ ano, dos 49 estudantes que participaram do estudo, 23 não receberam o estímulo da robótica, enquanto que 26 alunos receberam o estímulo. Analisando o desempenho do grupo de estudantes do $4^{\circ}$ ano que não receberam estímulo do robô, foi possível perceber uma grande dificuldade, refletida no baixo número de acertos, com relação às atividades L2, B-D2 e D-B2, conforme Figura 4.

Já o desempenho do grupo de estudantes do $4^{\circ}$ ano que recebeu estímulos da robótica foi melhor em relação ao grupo que não recebeu. Isso é evidente, pois os índices de acertos e de erros se mantiveram entre 20 a 26 e 1 a 4, respectivamente, conforme Figura 4.

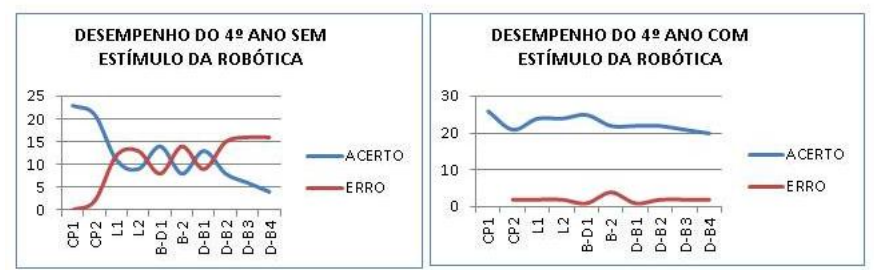

Figura 4 - Desempenho do $4^{\circ}$ ano.

Já sobre o grupo de estudantes do $5^{\circ}$ ano, do total de 30 estudantes participantes, 16 receberam o estímulo da robótica, enquanto que 14 não receberam o mesmo estímulo. Em relação ao grupo que não recebeu estímulos da robótica, 14 estudantes, o desempenho foi bom apenas nas questões CP1 e CP2, pois, a partir dessas, o nível de acerto diminuiu a 5 acertos nas questões que envolviam a conversão decimal-binária.

Por outro lado, o desempenho do grupo que recebeu estímulos da robótica foi melhor. $\mathrm{O}$ gráfico ilustrado na Figura 5 mostra que o número de acertos se manteve entre 11 e 16, bem acima em relação ao grupo que não obteve o estímulo da robótica.

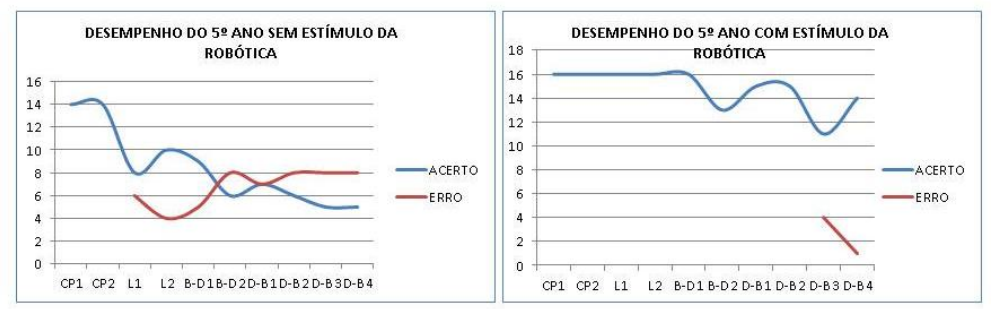

Figura 5 - Desempenho do 5 ano.

\section{Conclusões}

Este trabalho apresenta uma abordagem de importante contribuição à comunidade científica na área de estudo, tendo em vista discutir possibilidades de introduzir o pensamento computacional na escola e de desenvolver habilidades e competências fundamentais para este século.

Em relação aos resultados do estudo, foi possível indicar pontos a serem reforçados no aprendizado sobre tópicos da ciência da computação, aliando o ensino por atividades desplugadas e a robótica educativa, e promover o aprendizado efetivo de conceitos complexos de serem compreendidos apenas com aulas expositivas. 
VII Congresso Brasileiro de Informática na Educação (CBIE 2018)

Anais do XXIX Simpósio Brasileiro de Informática na Educação (SBIE 2018)

A aplicação da abordagem permitiu perceber e reforçar a necessidade de se trabalhar conteúdos correlatos da matemática ao mesmo tempo em que se aprende os conceitos computacionais, além de possibilitar o incentivo ao aprendizado tecnológico e o desenvolvimento de importantes habilidades, tais como a associação, a abstração e o uso de símbolos e metáforas.

\section{Referências}

Bell, T.; Whitten, I.; Fellows, M. Computer Science Unplugged.Universidade de Canterbury, Nova Zelândia, 2007.105 p. Disponível em: <http://csunplugged.org/>

Computer Science Teacher Association CSTA. (2005) The New Educational Imperative: Improving High School Computer Science Education. Final Report of the CSTA.Curriculum Improvement Task Force. ACM - Association for Computing Machinery.

Csizmadia, A.; Curzon, P.; Dorling, M.; Humphreys, S.; Thomas Ng; Selby, C.; Woollard, J.. (2015). Computational thinking: a guide for teachers. Computing At School.Disponívelem:<http://community.computingatschool.org.uk/files/6695/origin al.pdf $>$.

Da Silva, D. P. et al. (2016). Aplicação de robótica na educação de forma gradual para o estímulo do pensamento computacional. In Anais dos Workshops do CBIE 2016, páginas 1188-1197.

Gal-Ezer, J. and D. Harel.(1999) Curriculum for a high school computer science curriculum.Computer Science Education 9(2).

Ministério da Educação de Ontário - MEO. (2008). "Currículo para o ensino de Ciência da Computação nas escolas". Retirado de www.edu.gov.on.ca.

Neto, R. P. B., Santana, A. M., Rocha, D. P.; Souza, A. (2015). Robótica na educação: Uma revisão sistemática dos últimos 10 anos. In Anais do SBIE 2015, páginas 386395.

Oliveira, E.; Araujo, A. L. (2016). Pensamento computacional e robótica: Um estudo sobre habilidades desenvolvidas em oficinas de robótica educacional. In Anais do SBIE 2016, páginas 530-539.

Wing, J. M. (2006).Computational thinking.Commun. ACM, 49(3):33-35.

Zanetti, H.; Oliveira, C. (2015). Praticas de ensino de programação de computadores com robótica pedagógica e aplicação de pensamento computacional. In Anais dos Workshops do CBIE, páginas 1236-1245. 